\title{
The effects of prenatal stress and postweaning housing conditions on parental and sexual behavior of male Long-Evans rats
}

\author{
PETER J. MCLEOD and RICHARD E. BROWN \\ Dalhousie University, Halifax, Nova Scotia, Canada
}

\begin{abstract}
Male offspring of stressed and control female rats were housed in pairs with a control male or a female from 22 to 90 days of age, then they were screened for infanticide and tested for parental behavior and sexual behavior. Male rats housed with females were less likely to be infanticidal than males housed with other males, but prenatal stress had no effect on infanticide rate. Control males housed with males showed a longer latency to carry pups than did males in the other three groups, and there was a stress $\times$ days interaction in the frequency of parental behavior, with prenatally stressed males showing more parental behavior than control males after 4 days of pup exposure. In the male sexual behavior tests, prenatally stressed males had longer intromission latencies and shorter postejaculatory intervals than did control males, while males housed with females had fewer mounts without intromissions and shorter ejaculation latencies than did males housed with other males. Female sexual behavior was not influenced by stress or housing, but control males showed more aggression toward stud males than did stressed males. Stressed male rats had smaller testes than did control males. Correlations among these measures indicate that prenatal stress results in a general syndrome of behavioral change.
\end{abstract}

Environmental stress administered to female rats during the last week of their pregnancy feminizes and demasculinizes the sexual behavior of their male offspring. At maturity, prenatally stressed males copulate less than control males and, following castration and injection of estrogen and progesterone, show more lordotic responses than controls (Dahlöf, Hård, \& Larsson, 1977; Masterpasqua, Chapman, \& Lore, 1976; Meisel, Dohanich, \& I. L. Ward, 1979; Rhees \& Fleming, 1981; I. L. Ward, 1972). Prenatally stressed males also show reduced anogenital distance and reduced testes weights (Dahlöf, Hård, \& Larsson, 1978; Meisel et al., 1979). These effects appear to be due to changes in fetal testosterone levels (I. L. Ward \& Weisz, 1980, 1984), abnormal patterns of testicular steroidogenic enzymes (Orth, Weisz, Ward, \& Ward, 1983; Pollard \& Dyer, 1985), and reduced brain aromatase activity on days 18 to 20 of gestation (Weisz, Brown, \& I. L. Ward, 1982).

In the brain, prenatal stress delays the development of the noradrenergic neurons (Peters, 1984) and reduces the size of the sexually dimorphic nucleus of the preoptic area (SDN-POA) (D. K. Anderson, Rhees, \& Fleming, 1985). The reduced size of the SDN-POA is correlated with the lower testosterone levels and reduced sexual activity of the prenatally stressed male (R. H. Anderson, Fleming, Rhees, \& Kinghorn, 1986).

This research was supported by NSERC of Canada Grant A7441 and by the Dalhousie University Research Development Fund in the Sciences. Peter McLeod is now at the Psychology Department, University of British Columbia, Vancouver, British Columbia V6T 1Y7, Canada. Richard Brown's mailing address is Department of Psychology, Dalhousie University, Halifax, Nova Scotia B3H 4J1, Canada.
Although the majority of studies of prenatal stress have concentrated on sexual behavior (I. L. Ward, 1984; Ward \& Ward, 1985), some studies have shown that prenatally stressed males also show reductions in infanticide (Miley, Frank, \& Hoxter, 1981) and aggression (Harvey \& Chevins, 1985; Kinsley \& Svare, 1986). Little work has been done to examine the effects of prenatal stress on parental behavior of male rats.

Male rats are more likely than females to be infanticidal (Brown, 1986a; Jakubowski \& Terkel, 1985) and less likely to show parental behavior (Brown, 1986b; Mayer, Freeman, \& Rosenblatt, 1979; Quadagno \& Rockwell, 1972). This gender difference in parental behavior develops at puberty, and males become less responsive to pups between 30 and 90 days of age (Mayer et al., 1979). Neonatal castration reduces infanticide by male rats (K. M. Rosenberg, Denenberg, Zarrow, \& Frank, 1971) and increases parental responsiveness (McCullough, Quadagno, \& Goldman, 1974; Quadagno \& Rockwell, 1972; P. A. Rosenberg \& Herrenkohl, 1976). Thus, one would expect prenatal stress to decrease infanticide and increase parental behavior in males.

Some of the sexually dimorphic behaviors that can be altered by prenatal stress, including male sexual behavior and infanticide, are also influenced by postweaning social experience (Isaacson \& I. L. Ward, 1986; K. M. Rosenberg \& Sherman, 1975). Rearing conditions interact with prenatal stress to influence sexual behavior of male rats (Dunlap, Zadina, \& Gougis, 1978; I. L. Ward \& Reed, 1985).

Sexual experience and cohabitation with a pregnant female inhibit infanticide in male rats (Brown, 1986a), and 
social rearing conditions influence male behavior toward pups in other rodents (Gibber \& Terkel, 1985; Jakubowski $\&$ Terkel, 1982). We examined the interaction of prenatal stress and postweaning rearing conditions on the parental behavior of male rats. Following the parental behavior tests, the males were tested for sexual responsiveness.

\section{METHODS}

\section{Subjects}

Twenty-one nulliparous female Long-Evans hooded rats purchased from Charles River (St. Constant, Quebec, Canada) were screened each day for estrus, and when receptive, they were paired for $24 \mathrm{~h}$ with a stud male (Day 0 of gestation). The pregnant females then were housed individually in $24 \times 46 \times 16 \mathrm{~cm}$ plastic cages until Day 14 of gestation. They were provided with wood shavings for bedding, ad-lib Purina Lab Chow and water, and were kept on a reversed 14:10-h light:dark cycle with the lights off at 10:00 a.m. and on at 8:00 p.m. On Day 14 of pregnancy, 8 females were assigned at random to the stress group and 13 to the control group.

\section{Stressing Procedure}

Stressed females were placed for $45 \mathrm{~min}$ in a half-circular, cylindrical, adjustable-length Plexiglas restraining chamber $(25 \mathrm{~cm}$ long and $7.5 \mathrm{~cm}$ inside diameter) and exposed to bright light (two 150 -W white lights; approximately $2000 \mathrm{~lm} / \mathrm{m}^{2}$ ) three times daily $(0900,1300$, and $1700 \mathrm{~h})$ from Days 14 to 21 of gestation (I. L. Ward, 1972). The mean temperature under the lights, as recorded on the table beside the Plexiglas restraining chamber, was $29.3^{\circ} \mathrm{C}$ $\left( \pm 1.5^{\circ}\right)$. The control-group females were left unhandled in their home cages.

\section{Preweaning Rearing Conditions}

After birth (Day 0), all pups were kept with their own mother and littermates until 22 days of age. Six stressed females and 10 control females gave birth within 5 days of each other, and the pups from these litters served as subjects in the experiment. The average litter size at birth for the stressed females was 12.3 pups, $54 \%$ of which were male. The control litters averaged 12.8 pups, with $53 \%$ males. Neither the litter size $[t(14)=0.61]$ nor the sex ratio $[t(14)=0.14]$ were influenced by prenatal stress. When the pups were 2 days of age, litters with more than 12 pups were culled to 12 .

\section{Postweaning Rearing Conditions}

At weaning, half of the prenatally stressed and control males from each litter were housed with an unstressed male and half with an unstressed female. The animals were ear-punched for identification. During the rearing period, pairs of rats were housed in Wahman hanging cages $(18 \times 24.5 \times 18 \mathrm{~cm})$, with Purina Lab Chow and water available ad lib. The housing room was maintained on a 14:10h light:dark cycle. The females had their fallopian tubes tied at about 35 days of age to prevent pregnancy. When they were about 90 days of age, the males were housed individually in $24 \times 46 \times 16 \mathrm{~cm}$ plastic cages.

\section{Infanticide Test}

Four days after individual housing, all males were screened for infanticide by presenting them with two 1 to 3 day-old pups in their home cage for $12 \mathrm{~h}$. Another pair of pups was presented for a second 12-h period. The number of pups bitten or killed was recorded, and the males that killed 2 or more pups were classed as infanticidal and not used in the parental behavior tests (see Brown, 1986a, b).

\section{Parental Behavior Tests}

Immediately after the infanticide test, the noninfanticidal males from each group were given 3 pups and $202.5 \times 12 \mathrm{~cm}$ strips of paper towelling for nest material. The pups were replaced every $12 \mathrm{~h}$ with 3 littermates so that the males spent $24 \mathrm{~h}$ per day with pups. After the pup exchange in the dark phase of the light:dark cycle, the male's nest was rated on a 5-point scale (Brown, 1986b; Terlecki and Sainsbury, 1978). A rating of 3 or above indicated a good nest, which used most of the paper strips in a limited area of the cage. Old nest material was then removed, new paper strips added, and the male's parental behavior was observed for $15 \mathrm{~min}$.

Parental behaviors were recorded every $15 \mathrm{sec}$, using a timesampling procedure. The parental behaviors recorded included nest building, sniffing pups, crouching over pups, and carrying pups, as described in Brown (1986b). Whether or not the male was touching any pups was recorded independently of the other behaviors. Only one behavior was scored per 15 -sec interval, except for touching, which was scored in all intervals in which it occurred. Male parental behavior was observed once a day for 10 consecutive days. Observations were done without knowledge of which group the subjects belonged to, in a room dimly lit with white light.

\section{Male Sexual Behavior Tests}

Starting 2 days after the last parental behavior test, all males, whether infanticidal or not, received sexual behavior tests. Estrous females were presented to each male for 15 min each day in a $61 \times 29 \times 31 \mathrm{~cm}$ arena for 4 consecutive days. These tests were conducted during the dark phase of the light:dark cycle, using dim red light. An event recorder was used to score each mount (M), intromission (I), and ejaculation (E). From the event records, the number of males to ejaculate over the four tests and the total number of ejaculations per male over the four tests were calculated. For those males achieving at least one ejaculation, the following measures were taken on their first ejaculatory series: intromission latency (IL), mount frequency (MF), intromission frequency (IF), ejaculation latency (EL), postejaculatory interval (PEI), and mean interintromission interval (MIII) (Brown \& McFarland, 1979).

\section{Castration and Organ Weights}

Two days following male sexual behavior tests all males (about 105 days of age) were castrated under Somnitol anaesthesia (dose $=50 \mathrm{mg} / \mathrm{kg}$ ). The body weight of each male was recorded at this time and the testes and epididymes removed and weighed.

\section{Female Sexual Behavior Tests}

After a 4-day recovery period, each male received a subcutaneous "primer" injection of $50 \mu \mathrm{g}$ estradiol benzoate (EB, Sigma) in $0.1 \mathrm{ml}$ corn oil, followed $48 \mathrm{~h}$ later by $0.5 \mathrm{mg}$ progesterone $(\mathrm{P}$, Sigma) in $0.1 \mathrm{ml}$ corn oil. Two days after the primer injection, the males again were injected with $50 \mu \mathrm{g} \mathrm{EB}$, and $42 \mathrm{~h}$ later with $0.5 \mathrm{mg}$ $P$. Four hours after the $P$ injection, each male was placed in the test arena with a stud male for $15 \mathrm{~min}$ or until 10 mounts occurred. Mounts by the stud male and the test male's response (lordosis, no response, or fighting) were scored on an event recorder. Lordosis intensity was rated on a 3-point scale, using the criterion of Hardy and DeBold (1971). Female sexual behavior tests were given once per week for 3 weeks.

\section{RESULTS}

\section{Infanticidal Behavior}

Two (12.5\%) of the 16 control males housed with males (Group CM) and $6(30 \%)$ of the 20 prenatally stressed males housed with males (Group SM) were infanticidal. None of the 14 control males housed with females (Group CF) and none of the 15 prenatally stressed males housed with females (Group SF) killed pups. Thus, there was a significant effect of rearing condition on infanti- 
Table 1

Median Latency (and Interquartile Range) in Days for Male Rats Showing Parental Behaviors in Each Group

\begin{tabular}{llllll}
\multicolumn{5}{c}{ Showing Parental Behaviors in Each Group } \\
\cline { 2 - 5 } \multicolumn{5}{c}{ Behavior } & \multicolumn{1}{c}{ CM } \\
\cline { 2 - 5 }$(n=10)$ & $(n=12)$ & $\begin{array}{c}\text { CF } \\
(n=10)\end{array}$ & $\begin{array}{c}\text { SF } \\
(n=11)\end{array}$ & $H$ \\
\hline Touch pups & 1 (all 1) & $1(1-2)$ & $1(1-2)$ & $1(1-2)$ & 1.54 \\
Nest build & $1.5(1-2)$ & $1(1-2)$ & $1(1-2)$ & $1(1-2)$ & 0.86 \\
Sniff pups & $1($ all 1$)$ & $1($ all 1$)$ & $1($ all 1$)$ & $1($ all 1$)$ & 0.18 \\
Lick pups & $2(2-7)$ & $5(3-8)$ & $6.5(4-8)$ & $5(4-6)$ & 2.32 \\
Crouch over pups & $3(1-6)$ & $5(2-9)$ & $4.5(2-5)$ & $2(2-6)$ & 0.13 \\
Carry pups & $11+(10-11+)$ & $7(2-9)$ & $7(5-8)$ & $5(2-9)$ & $9.40^{*}$ \\
\hline
\end{tabular}

Note-CM $=$ control males housed with males. $\mathbf{C F}=$ control males housed with females. $\mathrm{SM}=$ prenatally stressed males housed with males. $\mathrm{SF}=$ prenatally stressed males housed with females. $\quad{ }^{*} p<.05$, KruskalWallis test.

cide rate $\left[x^{2}(1)=5.43, p<.02\right]$, but no effect of prenatal stress $\left[x^{2}(1)=0.82\right]$.

\section{Parental Behavior Tests}

All of the noninfanticidal males were tested for parental behavior, but data were analyzed for only the males that were observed for 10 days. The sample size for each group is shown in the tables.

\section{Latency to Show Parental Behavior}

Table 1 shows the median latency in days for males in the four groups to display each parental behavior. The males that did not show the behavior during the 10 days of observation were given a score of $11+$. There were significant differences among groups only in their latency to carry pups (Kruskal-Wallis, $H=9.40, p<.05$ ). Mann-Whitney $U$ tests indicated that both groups of stressed males carried pups earlier than did the control males housed with males $(z>2.65, p<.01)$, as did the control males housed with females $(z=2.11, p<.05)$. None of the other three groups (SF, SM, or CF) differed in latency to carry pups.

\section{Frequency of Parental Behavior}

The mean frequency of each parental behavior over the 10 days of observation was analyzed by a 2 (stress) $\times$ 2 (rearing) $\times 10$ (days) split-plot analysis of variance (ANOVA). The results are summarized in Table 2.

\section{Touch Pups}

There was a significant increase in the frequency of touching pups over days $[F(9,351)=11.24, p<.001]$, and a stress $\times$ days interaction $[F(9,351)=2.01$, $p<.05]$. There was no significant effect of rearing condition on touching pups nor were any other interactions significant, so the analysis was repeated as a $2 \times 10$ ANOVA to examine the stress $x$ days interaction (Figure 1). This analysis repeated the significant days effect $[F(9,369)=11.23, p<.001]$ and the stress $\times$ days interaction $[F(9,369)=2.02, p<.05]$. Post-hoc Tukey's tests (Kirk, 1968, p. 268) showed that the stressed males touched the pups less than did the controls on Day 2 and more than did the controls on Days 6 and $8(p<.05)$.

\section{Nest Building and Nest Rating}

Nest building increased over days $[F(9,351)=3.99$, $p<.001]$, but was not influenced by prenatal stress or rearing condition, nor were there any significant interactions. Likewise, nest ratings increased over days $[F(9,351)$ $=12.28, p<.001]$, but there were no significant effects of prenatal stress or rearing conditions, nor were there any significant interactions.

\section{Sniff Pups}

Sniffing pups showed significant changes over days $[F(9,351)=3.98, p<.001]$, but these changes were unsystematic. There were no effects of prenatal stress or

Table 2

Mean Frequency of Observations Per Day of Parental Behavior by Male Rats in Each Group

\begin{tabular}{|c|c|c|c|c|c|c|c|c|}
\hline \multirow[b]{3}{*}{ Behavior } & \multicolumn{8}{|c|}{ Group } \\
\hline & \multicolumn{2}{|c|}{$\begin{array}{c}\mathrm{CM} \\
(n=10)\end{array}$} & \multicolumn{2}{|c|}{$\begin{array}{c}\text { CF } \\
(n=12)\end{array}$} & \multicolumn{2}{|c|}{$\begin{array}{c}\text { SM } \\
(n=10)\end{array}$} & \multicolumn{2}{|c|}{$\begin{array}{c}\text { SF } \\
(n=11)\end{array}$} \\
\hline & $M$ & $S E M$ & $M$ & $S E M$ & $M$ & SEM & $M$ & $S E M$ \\
\hline Touch pups & 15.6 & 4.5 & 12.5 & 3.2 & 13.4 & 3.2 & 16.6 & 4.1 \\
\hline Nest build & 3.5 & 2.0 & 3.8 & 1.6 & 6.4 & 2.8 & 4.3 & 2.2 \\
\hline Nest rating & 1.5 & 0.3 & 1.7 & 0.4 & 1.8 & 0.3 & 1.8 & 0.3 \\
\hline Sniff pups & 10.6 & 1.7 & 11.3 & 1.4 & 9.7 & 1.4 & 9.7 & 1.5 \\
\hline Parental behavior & 7.5 & 3.6 & 7.0 & 2.9 & 6.6 & 2.8 & 10.7 & 3.5 \\
\hline
\end{tabular}

Note-CM $=$ control males housed with males. $\mathrm{CF}=$ control males housed with females. SM $=$ prenatally stressed males housed with males. $\mathrm{SF}=$ prenatally stressed males housed with females. Parental behavior includes licking, crouching over, and carrying pups. 


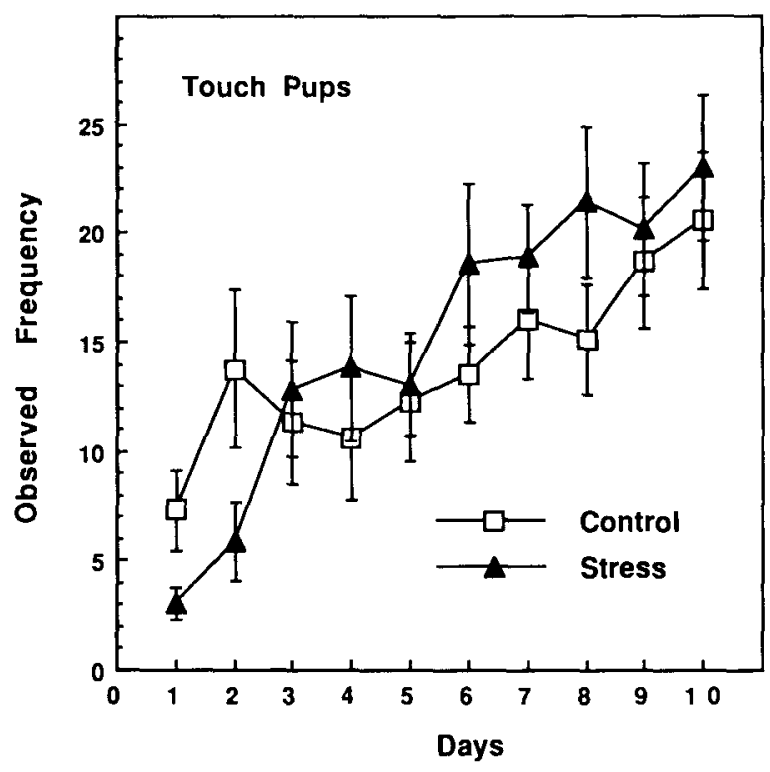

Figure 1. Mean ( \pm SEM) observed frequency of touching pups for control and stressed male rats over the 10 days of observation.

rearing condition on the frequency of sniffing pups, and no significant interactions.

\section{Active Parental Behavior}

The frequency of active parental behavior (lick, crouch over, and carry pups) increased over days $[F(9,351)=$ $6.91, p<.001]$ and showed a significant stress $\times$ days interaction $[F(9,351)=2.11, p<.03]$. Since no other interactions were significant, the stress $\times$ days interaction was examined using a $2 \times 10$ ANOVA (Figure 2 ). This replicated the previous analysis in showing a significant days effect $[F(9,369)=7.75, p<.01]$ and a stress $\times$ days interaction $[F(9,369)=2.33, p<.02]$. The results of Tukey's tests indicate that the stressed males showed less parental behavior than did the control males on Day 2 of observation $(p<.05)$ and more parental behavior on Days 4 and $6(p<.05)$.

\section{Male Sexual Behavior Tests}

The results of the tests of male sexual behavior are shown in Table 3 . These data were analyzed by 2 (stress) $\times 2$ (rearing) ANOVAs.

There were no effects of prenatal stress or rearing conditions on ejaculation frequency over the four tests, nor were there any significant stress $\times$ rearing interactions. Likewise, there were no differences among groups in the number of tests in which an ejaculation occurred (Table 3). When sexual behavior on the first ejaculatory series was analyzed, the prenatally stressed males had longer intromission latencies than did the control males $[F(1,46)$ $=5.71, p<.02]$, but shorter postejaculatory intervals $[F(91,42)=4.97, p<.05]$ (Table 3).

Rearing condition had a significant influence on the frequency of mounts without intromission (MF) and ejacu- lation latency (EL). The males reared with females had fewer mounts without intromissions than did those reared with the control males $[F(1,47)=4.56, p<.05]$ and had shorter ejaculation latencies $[F(1,47)=6.21$, $p<.02$ ] (Table 3). Intromission frequency (IF) and mean interintromission interval (MIII) were not influenced by prenatal stress or rearing condition, and there were no significant stress $\times$ rearing interactions for any measure of male sexual behavior.

\section{Female Sexual Behavior Tests}

The responses of the test males to the stud males were pooled over the three female sexual behavior tests, and a lordosis quotient (LQ) was calculated for the males receiving 10 or more mounts over the three tests. The males received a mean $( \pm S E M)$ of $22.4 \pm 1.5$ mounts by the stud males over the three tests, to which they could respond by fighting, no lordosis, or lordosis, ranked in intensity from 1 to 3 . The proportion of the males showing an LQ of 15 or more (I. L. Ward \& Reed, 1985) over the three tests (Table 4) did not differ among the four groups $\left[x^{2}(3)=0.35\right]$. When the LQ was calculated from all lordosis responses rated at 1 or more (Table 4), there were no differences among groups in LQ and no significant interaction (all $F \mathrm{~s}<1.0$ ). Likewise, when only lordosis responses ranked 2 or 3 were used to calculate the LQ, there were no significant differences among groups (Table 4).

There was, however, a significant effect of prenatal stress on aggressive responses toward the stud male $[F(1,46)=4.96, p<.05]$. The control males fought the stud males more than did the prenatally stressed males (Table 4). Rearing condition did not influence aggressive

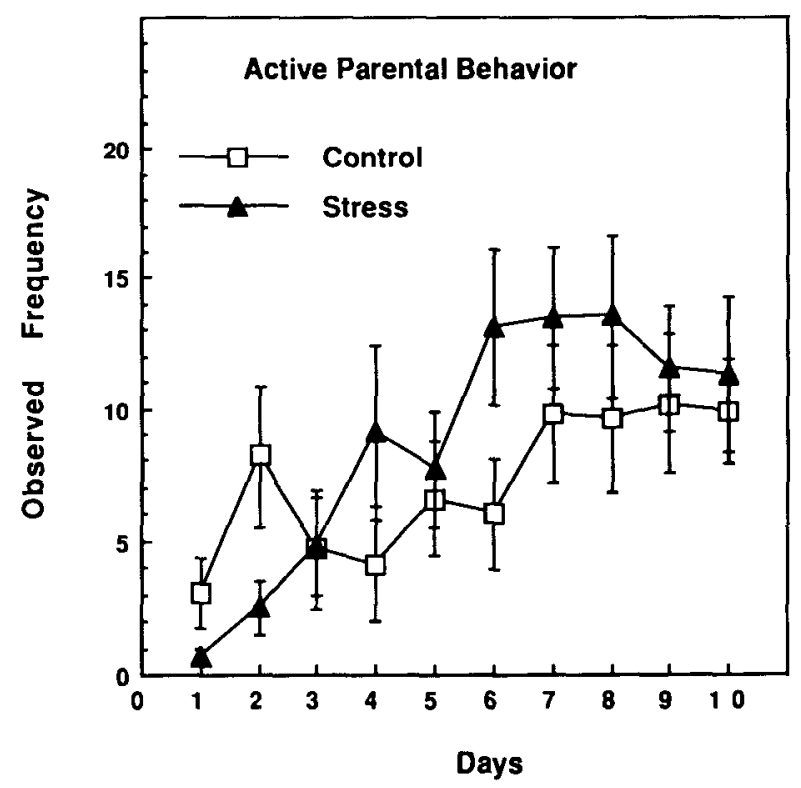

Figure 2. Mean $( \pm S E M)$ observed frequency of active parental behavior (licking, crouching over, and carrying pups) for control and stressed male rats over the $\mathbf{1 0}$ days of observation. 
Table 3

Mean Ejaculation Frequency Over the Four Male Sexual Behavior Tests and Number of Tests with Ejaculations for the Male Rats, and Mean Sexual Behavior Scores for the Male Rats' First Complete Ejaculatory Series

\begin{tabular}{|c|c|c|c|c|c|c|c|c|}
\hline & \multicolumn{8}{|c|}{ Group } \\
\hline & \multicolumn{2}{|c|}{$\begin{array}{c}\mathrm{CM} \\
(n=14)\end{array}$} & \multicolumn{2}{|c|}{$\begin{array}{c}\text { CF } \\
(n=14) \\
\end{array}$} & \multicolumn{2}{|c|}{$\begin{array}{c}\text { SM } \\
(n=17)\end{array}$} & \multicolumn{2}{|c|}{$\begin{array}{c}\text { SF } \\
(n=14)\end{array}$} \\
\hline & $M$ & $S E M$ & $M$ & $S E M$ & $M$ & $S E M$ & $M$ & $S E M$ \\
\hline Ejaculation frequency & 2.3 & 0.5 & 3.3 & 0.5 & 2.6 & 0.4 & 2.9 & 0.5 \\
\hline Tests with ejaculations & 1.6 & 0.3 & 2.5 & 0.4 & 2.0 & 0.2 & 2.0 & 0.3 \\
\hline
\end{tabular}

Scores on the First Ejaculatory Series

\begin{tabular}{lrrrrrrrc} 
Intromission latency* & 47.4 & 12.4 & 58.8 & 16.3 & 79.3 & 14.4 & 103.7 & 21.0 \\
Mount frequency & 14.5 & 2.6 & 8.0 & 1.8 & 13.5 & 2.4 & 11.2 & 1.1 \\
Intromission frequency $^{*}$ & 9.2 & 1.9 & 9.2 & 1.4 & 7.5 & 0.9 & 7.5 & 1.4 \\
Ejaculation latency* $^{*}$ & 543 & 57 & 380 & 63 & 499 & 62 & 373 & 40 \\
Interintromission interval* $^{*}$ & 83.8 & 16.7 & 48.7 & 7.4 & 76.6 & 10.9 & 76.9 & 16.9 \\
Postejaculatory interval* $^{*}$ & 328 & 19.8 & 334 & 19.3 & 291 & 12.7 & 300 & 11.4 \\
\hline
\end{tabular}

Note-CM $=$ control males housed with males. $\mathrm{CF}=$ control males housed with females. SM $=$ prenatally stressed males housed with males. $\mathrm{SF}=$ prenatally stressed males housed with females. $\quad$ In seconds.

responses, nor was there a significant stress $\times$ rearing interaction.

\section{Morphological Measures}

There were no significant differences in body weight among the four groups (Table 5). Results of a $2 \times 2$ ANOVA showed that the testes weights of the prenatally stressed males were significantly lower than those of the control males $[F(1,55)=11.54, p<.01]$, but there was no effect of rearing and no stress $\times$ rearing interaction. Epididymes weights did not differ significantly among groups.

\section{Correlations Among Measures}

In a "feminized" male, one would expect a higher frequency of parental behavior and touching pups, lower ejaculation frequency, higher LQ, fewer fights, and lower testes weights. Table 6 shows the correlations among these measures for the control and the stressed males. In both the stressed and the control males, the highest correlations were between the mean frequency of touching pups and active parental behavior. In the control males, parental behavior and LQ were negatively correlated with num- ber of fights. Parental behavior was positively correlated with both ejaculation frequency and LQ, but neither of these correlations were significant.

The stressed males showed a significant positive correlation between parental behavior and LQ, and significant negative correlations between parental behavior and testes weight and between LQ and number of fights. They also showed a significant positive correlation between testes weight and ejaculation frequency. Touching pups was positively correlated with ejaculation frequency and LQ, but these correlations did not reach significance.

\section{DISCUSSION}

This study examined the effects of prenatal stress and postweaning rearing conditions on body morphology and five sexually dimorphic behaviors: infanticide, parental behavior, male sexual behavior, female sexual behavior, and aggression.

\section{Infanticide}

Since neonatal castration reduces infanticide (K. M. Rosenberg et al., 1971; K. M. Rosenberg, 1974) and

Table 4

Percentage of Male Rats Showing Lordosis Quotients (LQs) of 15 or more, Mean LQs, and Number of Fights Shown by Male Rats in Each Group

\begin{tabular}{|c|c|c|c|c|c|c|c|c|}
\hline & \multicolumn{8}{|c|}{ Group } \\
\hline & \multicolumn{2}{|c|}{$\begin{array}{c}\text { CM } \\
(n=14)\end{array}$} & \multicolumn{2}{|c|}{$\begin{array}{c}\text { CF } \\
(n=13)\end{array}$} & \multicolumn{2}{|c|}{$\begin{array}{c}\text { SM } \\
(n=16)\end{array}$} & \multicolumn{2}{|c|}{$\begin{array}{c}\text { SF } \\
(n=13)\end{array}$} \\
\hline & $M$ & $S E M$ & $M$ & $S E M$ & $M$ & $S E M$ & $M$ & SEM \\
\hline $\begin{array}{l}\text { Percentage with } \\
\text { LQ } \geq 15 \\
\text { Mean LQ with }\end{array}$ & \multicolumn{2}{|c|}{77} & \multicolumn{2}{|c|}{70} & \multicolumn{2}{|c|}{86} & \multicolumn{2}{|c|}{77} \\
\hline $\begin{array}{l}\text { intensity } \geq 1 \\
\text { Mean LQ with }\end{array}$ & 63.9 & 8.9 & 63.6 & 11.6 & 69.4 & 5.6 & 61.8 & 8.2 \\
\hline intensity $\geq 2$ & 45.4 & 9.4 & 44.6 & 10.6 & 47.4 & 7.9 & 48.7 & 8.2 \\
\hline Mean number of fights & 5.5 & 2.2 & 5.4 & 1.9 & 1.9 & 1.0 & 2.2 & 0.8 \\
\hline
\end{tabular}


Table 5

Mean Body Weight, Testes Weight, and Epididymes Weight of Rats in Each Group

\begin{tabular}{|c|c|c|c|c|c|c|c|c|}
\hline & \multicolumn{8}{|c|}{ Group } \\
\hline & \multicolumn{2}{|c|}{$\begin{array}{c}\text { CM } \\
(n=14)\end{array}$} & \multicolumn{2}{|c|}{$\begin{array}{c}C F \\
(n=14)\end{array}$} & \multicolumn{2}{|c|}{$\begin{array}{c}\mathrm{SM} \\
(n=17)\end{array}$} & \multicolumn{2}{|c|}{$\begin{array}{c}\text { SF } \\
(n=14)\end{array}$} \\
\hline & $M$ & $\overline{S E M}$ & $M$ & $S E M$ & $M$ & $S E M$ & $M$ & $\overline{S E M}$ \\
\hline Body weight (g) & 376.4 & 8.8 & 398.6 & 11.9 & 372.0 & 7.7 & 381.7 & 7.8 \\
\hline Testes weight (g) & 3.8 & 0.1 & 4.0 & 0.1 & 3.7 & 0.06 & 3.6 & 0.08 \\
\hline Epididymes weight (g) & 1.27 & 0.03 & 1.32 & 0.03 & 1.26 & 0.02 & 1.24 & 0.02 \\
\hline
\end{tabular}

Note $-\mathrm{CM}=$ control males housed with males. $\mathrm{CF}=$ control males housed with females. $\mathrm{SM}$

$=$ prenatally stressed males housed with males. $S F=$ prenatally stressed males housed with females.

prenatal stress reduces pup killing (Miley et al., 1981), we felt that stressed males would be less likely to kill pups than would control males. Rearing condition, however, was more important than prenatal stress in suppressing infanticide. Postweaning cohabitation with females thus inhibits infanticide in male rats, as it does with hamsters and mice (Gibber \& Terkel, 1985; Jakubowski \& Terkel, 1982). Inhibition of infanticide in adult male rats also occurs after mating and cohabiting with a pregnant female (Brown, 1986a). Prenatal stress has, however, been shown to reduce infanticide in mice (Vom Saal, 1983) and rats (Miley et al., 1981).

\section{Parental Behavior}

Rearing condition had no effect on parental behavior. This supports the results of a previous study (Brown, 1986b) that found that sexual experience and cohabitation with a pregnant female had no effect on the frequency of parental behavior in male rats, although this experience inhibited infanticide.

The prenatally stressed males showed a shorter latency to carry pups than did the control males, and a greater

Table 6

Correlations Among Behavioral Responses and Testes Weights (TW) for Control and Stressed Male Rats

\begin{tabular}{lrrrrr}
\hline & PB & EF & LQ & F & TW \\
\hline & Control Males & & & \\
Touch pups (TP) & $.85 \ddagger$ & .14 & .31 & -.26 & .15 \\
Parental behavior (PB) & & .35 & .28 & $-.42 \dagger$ & .12 \\
Ejaculation frequency (EF) & & -.07 & -.34 & .15 \\
Lordosis quotient (LQ) & & & $-.41^{*}$ & .01 \\
Number of fights (F) & & & & & -.01 \\
Testes weight (TW) & & & & & -
\end{tabular}

Stressed Males

\begin{tabular}{|c|c|c|c|c|c|}
\hline Touch pups (TP) & $.81 \ddagger$ & .34 & .33 & .13 & -.04 \\
\hline Parental behavior (PB) & & .01 & $.44^{*}$ & -.10 & $-.38 *$ \\
\hline Ejaculation frequency (EF) & & & .02 & .35 & $.46 \dagger$ \\
\hline Lordosis quotient (LQ) & & & & $-.39 *$ & -.04 \\
\hline Number of fights (F) & & & & & .25 \\
\hline Testes weight (TW) & & & & & - \\
\hline
\end{tabular}

Note-Mean number of observations of touching pups (TP) and active parental behavior (PB) per day; total ejaculations over four tests (EF); mean lordosis quotient over three tests (LQ) and total number of fights (F) over three tests were used for the calculations. ${ }^{*} p<.05$, onetail; $\dagger p<.025 ; \ddagger p<.01$. frequency of touching pups and displaying active parental behavior, although these latter effects were not apparent until after 4 days of pup exposure. These results indicate that the parental behavior of the male rats was feminized to a slight degree. Not all parental behaviors were increased in prenatally stressed males, however. There was no effect on the latency to touch, lick, or crouch over pups, and no difference in nest-building frequency or nest rating. Kinsley and Bridges (1988) also have shown that prenatally stressed male rats have a more rapid onset of parental behavior than do control males. Likewise, prenatally stressed mice are more likely to show parental behavior than are control males (Vom Saal, 1983).

\section{Male Sexual Behavior}

There was no significant effect of prenatal stress or rearing condition on the number of males ejaculating or the frequency of ejaculations. I. L. Ward (September, 1986, personal communication) also has failed to find demasculinizing effects of prenatal stress with Long-Evans rats. Other studies show variability in the degree of decrement of male sexual behavior following prenatal stress. Dahlöf et al. (1977) found no differences in the proportion of prenatally stressed and control males that ejaculated. Our stressed males were reared with control males rather than with other stressed males, which may explain their elevated copulatory behavior (I. L. Ward \& Reed, 1985).

We did, however, find that the prenatally stressed males showed longer intromission latencies and reduced postejaculatory intervals. The longer intromission latencies may indicate a reduced level of sexual arousal, or competition between some other behavior and sexual arousal (Brown \& McFarland, 1979). The reduced postejaculatory interval in the stressed males indicates that they had a shorter refractory period than did the control males. Dahlöf et al. (1977) found that prenatally stressed males differed significantly from controls only in the number of mounts before ejaculation and in ejaculation latency, but not in mount latency or intromission latency, and these differences disappeared by the second series of mating tests. Masterpasqua et al. (1976) found a reduction in mount frequency, intromission frequency, and ejaculation frequency in prenatally stressed males and an increase in "inappropriate mounts." Rhees and Fleming (1981), however, found an increase in mount and in- 
tromission frequency in prenatally stressed males. Thus, the effect of prenatal stress on the performance of sexual behavior in males that ejaculate is inconsistent.

Rearing with females reduced the number of mounts without intromissions on the first ejaculatory series and, thus, the ejaculation latency. This improved copulatory performance might have been the result of sexual experience, since the males reared with females could mate with them. I. L. Ward and Reed (1985) found an interaction between prenatal stress and rearing condition on intromission latency, but no effect of either variable on mount frequency, intromission frequency, ejaculation latency, or postejaculatory interval.

Normal sexual behavior develops in some prenatally stressed males that are housed in adulthood with prepubertal females for 2 weeks, when the stressed males have not been reared in isolation prepubertally (Dunlap et al., 1978). In most prenatally stressed males, the deficit in sexual behavior still is evident after repeated access to estrous females (I. L. Ward, 1984). Masterpasqua et al. (1976), however, reported that their prenatal-stress procedure did not cause a permanent detriment to male sexual behavior, because $95 \%$ of their prenatally stressed males produced offspring when housed for 18 days with females.

\section{Female Sexual Behavior}

The prenatally stressed males in this study did not show higher LQs than the control males. All groups of males in our study showed higher LQs than those in I. L. Ward and Reed's (1985) study, particularly the control males. Thirty percent of the males in their Group CM and 77\% of our males in this group had an LQ of 15 or more. Likewise, $50 \%$ of their Group CF and $70 \%$ of our males in this group had an LQ of 15 or more (Table 4). Meisel et al. (1979) found an LQ of 51 in stressed males and an LQ of 7 in control males. Rhees and Fleming (1981) found an LQ of 38.3 in their stressed males and 8.9 in their controls. Dahlöf et al. (1977) found only $16 \%$ of their control males showed lordosis and $67 \%$ of their stressed males. Thus, our stressed males showed a high LQ relative to other studies, but our control males also showed a very high $L Q$, thus eliminating any effects of stress.

Contrary to I. L. Ward and Reed (1985), we did not find stressed males housed with females to be less likely to show lordosis, nor did we get a higher percentage of control males housed with females displaying lordosis. Several potentially important procedural differences, however, must be considered in comparing our results with those of I. L. Ward and Reed (1985). They used Sprague-Dawley rats, weaned them at 16 days of age, allowed the females housed with the males to become pregnant and give birth (at which time the pups were removed), had their male-male groups housed in a separate room with no female odors, and gave higher doses of steroids in the female sexual behavior tests. As rat strains differ in sexual performance (McLean, Dupeire, \& Elder, 1972) and parental responsiveness to pups (Jakubowski \& Terkel, 1985), they also may differ in their susceptibility to prenatal stress effects on both male and female sexual behavior. Strain differences influence the effects of prenatal stress on aggression in mice (Kinsley \& Svare, 1987).

\section{Aggressive Behavior}

During the female sexual behavior tests, the control males showed significantly more aggressive responses toward the stud male than did the stressed males, indicating that prenatal stress reduced their agonistic behavior. Prenatally stressed mice also are less aggressive toward a standard opponent than are unstressed controls (Harvey $\&$ Chevins, 1985; Kinsley \& Svare, 1986).

\section{Morphological Measures}

Prenatal stress reduced testes weight, but we found no effect of rearing condition on body or epididymes weights. Dahlöf et al. (1978) found that prenatal stress reduced body, testes, and adrenal weights in newborn males, and Meisel et al. (1979) found lower body, testes, and epididymes weights in prenatally stressed males at 115 days of age. Our finding of smaller testes in stressed males suggests that adult androgen levels might have differed among groups. McCullough et al. (1974), however, found that the testicular hormone levels at the time of testing were not a factor in determining the level of male parental behavior; testicular hormones during the neonatal period were more important.

The correlations between behavior and testes weight of the stressed males suggests that all males were not equally affected by the prenatal-stress procedure. Those that were more demasculinized had lower testes weights and showed higher levels of parental behavior, while those with higher testes weights showed more male sexual behavior. Those prenatally stressed males that showed the greatest lordosis response in female sexual behavior tests were less likely to be aggressive toward the stud male and more likely to show parental behavior.

These results indicate that prenatal stress does indeed result in a general behavioral syndrome (I. L. Ward, 1984), but they also indicate a wide variability in the degree to which individual males are influenced by prenatal stress. Such individual variability may be due to differences in the prenatal-stress procedure (Joffe, 1978), individual differences in the mother's susceptibility to stress, differences in levels of endorphins in the stressed females (O. B. Ward, Monaghan, \& I. L. Ward, 1986), or the intrauterine position of each male (Meisel \& I. L. Ward, 1981). Male Long-Evans rats appear to be less susceptible to the demasculinizing effects of prenatal stress than do Wistar or Sprague-Dawley males. This strain difference may be exacerbated by differences in the maternal care of stressed infants (Moore \& Power, 1986) and 
the level of stress used in different studies. Low levels of prenatal stress may facilitate, rather than inhibit, male sexual behavior (Rojo, Marin, \& Menendez-Patterson, 1985).

\section{REFERENCES}

Anderson, D. K., RheEs, R. W., Fleming, D. E. (1985). Effects of prenatal stress on differentiation of the sexually dimorphic nucleus of the preoptic area (SDN-POA) of the rat brain. Brain Research, 332, 113-118.

Anderson, R. H., Fleming, D. E., Rhees, R. W., \& Kinghorn, E. (1986). Relationships between sexual activity, plasma testosterone, and the volume of the sexually dimorphic nucleus of the preoptic area in prenatally stressed and non-stressed rats. Brain Research, 370, 1-10.

BRown, R. E. (1986a). Social and hormonal factors influencing infanticide and its suppression in adult male Long-Evans rats (Rattus norvegicus). Journal of Comparative Psychology, 100, 155-161.

Brown, R. E. (1986b). Paternal behavior in the male Long-Evans rat (Rattus norvegicus). Journal of Comparative Psychology, 100, 162-172.

BROWN, R. E., \& MCFARLAND, D. J. (1979). Interaction of hunger and sexual motivation in the male rat: A time-sharing approach. Animal Behaviour, 27, 887-896.

DAHLÖF, L. -G., HÄRD, E., \& LARSSON, K. (1977). Influence of maternal stress on offspring sexual behaviour. Animal Behaviour, 25, 958-963.

DAHLöF, L. -G., HÄRD, E., \& LARSSON, K. (1978). Influence of maternal stress on the development of the fetal genital system. Physiology \& Behavior, 20, 193-195.

Dunlap, J. L., Zadina, J. E., \& Gougis, G. (1978). Prenatal stress interacts with prepuberal social isolation to reduce male copulatory behavior. Physiology \& Behavior, 21, 873-875.

GibBer, J. R., \& TERKEL, J. (1985). Effect of postweaning social experience on response of Siberian hamsters. (Phodopus sungorus sungorus) toward young. Journal of Comparative Psychology, 99, 491-493.

HARDY, D. F., \& DeBold, J. F. (1971). Effects of mounts without intromission upon the behavior of female rats during the onset of estrogen-induced heat. Physiology \& Behavior, 7, 643-645.

Hakvey, P. W., \& Chevins, P. F. D. (1985). Crowding pregnant mice affects attack and threat behavior of male offspring. Hormones \& Behavior, 19, 86-97.

IsAaCsON, M. D., \& WARD, I. L. (1986). Prepuberal social rearing conditions and sexual behavior in control and neonatally castrated male rats. Physiology \& Behavior, 37, 469-473.

JAKUBOWSKI, M., \& TERKEL, J. (1982). Infanticide and caretaking in nonlactating Mus musculus: Influence of genotype, family group and sex. Animal Behaviour, 30, 1029-1035.

JAKUBOWSKI, M., \& TERKEL, J. (1985). Incidence of pup killing and parental behavior in virgin female and male rats (Rattus norvegicus): Differences between Wistar and Sprague-Dawley stocks. Journal of Comparative Psychology, 99, 93-97.

JoFFE, J. M. (1978). Hormonal mediation of the effects of prenatal stress on offspring behavior. In G. Gottlieb (Ed.), Studies on the development of behavior and the nervous system, Volume 4: Early influences (pp. 107-144). New York: Academic Press.

KINSLEY, C. H., \& BRIDGES, R. S. (1988). Prenatal stress and maternal behavior in intact virgin rats: Response latencies are decreased in males and increased in females. Hormones \& Behavior, 22, 76-89.

KINSLEY, C. H., \& SvARE, B. (1986). Prenatal stress reduces intermale aggression in mice. Physiology \& Behavior, 36, 783-786.

KINSLEY, C., \& SvARE, B. (1987). Genotype modulates prenatal stress effects on aggression in male and female mice. Behavioral \& Neural Biology, 47, 138-150.

KIRK, R. E. (1968). Experimental design: Procedures for the behavioral sciences. Belmont, California: Brooks/Cole.

Masterpasqua, F., Chapman, R. H., \& Lore, R. K. (1976). The ef- fects of prenatal psychological stress on the sexual behavior and reactivity of male tats. Developmental Psychobiology, 9, 403-411.

Mayer, A. D., Freeman, N. C. G., \& Rosendlatt, J. S. (1979). Ontogeny of maternal behavior in the laboratory rat: Factors underlying changes in responsiveness from 30 to 90 days. Developmental Psychobiology, 12, 425-439.

McCullough, J., Quadagno, D. M., \& Goldman, B. D. (1974). Neonatal gonadal hormones: Effect on maternal and sexual behavior in the male rat. Physiology \& Behavior, 12, 183-188

Mclean, J. H., Dupeire, W. A., III, \& Elder, S. T. (1972). Strain differences in the mating behavior of Sprague-Dawley, Long-Evans, and Wistar male rats. Psychonomic Science, 29, 175-176.

Meisel, R. L., Dohanich, G. P., \& WARD, I. L. (1979). Effects of prenatal stress on avoidance acquisition, open-field performance and lordotic behavior in male rats. Physiology \& Behavior, 22, 527-530.

MEISEL, R. L., \& WARD, I. L. (1981). Fetal female rats are masculinized by male littermates located caudally in the uterus. Science, 213 , 239-242.

Miley, W. M., Frank, M., \& Hoxter, A. L. (1981). Rat-pup killing and maternal behavior in male Long-Evans rats: Prenatal stimulation and postnatal testosterone. Bulletin of the Psychonomic Society, 17, 119-122.

MoORe, C. L., \& Power, K. L. (1986). Prenatal stress affects motherinfant interaction in Norway rats. Developmental Psychobiology, 19, 235-245.

Orth, J. M., WeISz, J., WARD, O. B., \& WARD, I. L. (1983). Environmental stress alters the developmental pattern of $\Delta 5-3 \beta$-hydroxysteroid dehydrogenase activity in Leydig cells of fetal rats: A quantitative cytochemical study. Biology of Reproduction, 28, 625-631.

Peters, D. A. V. (1984). Prenatal stress: Effect on development of rat brain adrenergic receptors. Pharmacology, Biochemistry \& Behavior, 21, 417-422.

Pollard, I., Dyer, S. L. (1985). Effect of stress administered during pregnancy on the development of fetal testes and their subsequent function in the adult rat. Journal of Endocrinology, 107, 241-245.

QuadaGno, D. M., Rockwell, J. (1972). The effect of gonadal hormones in infancy on maternal behavior in the adult rat. Hormones \& Behavior, 3, 55-62.

RHEEs, R. W., \& Fleming, D. E. (1981). Effects of malnutrition, maternal stress, or ACTH injections during pregnancy on sexual behavior of male offspring. Physiology \& Behavior, 27, 879-882.

Rojo, M., Marin, B., \& Menendez-Patterson, A. (1985). Effects of low stress during pregnancy on certain parameters of the offspring. Physiology \& Behavior, 34, 895-899.

RosenberG, K. M. (1974). Effects of pre- and postpubertal castration and testosterone on pup-killing behaviour in the male rat. Physiology \& Behavior, 13, 159-161.

Rosenberg, K. M., Denenberg, V. H., Zarrow, M. X., Frank, B. L. (1971). Effects of neonatal castration and testosterone on the rat's pup-killing behavior and activity. Physiology \& Behavior, 7 , 363-368.

Rosenberg, K. M., \& Sherman, G. F. (1975). Influence of testosterone on pup killing in the rat is modified by prior experience. Physiology \& Behavior, 15, 669-672.

RosenberG, P. A., \& Herrenkohl, L. R. (1976). Maternal behavior in male rats: Critical times for the suppressive action of androgens. Physiology \& Behavior, 16, 293-297.

Terlecki, L. J., \& SainsBury, R. S. (1978). Effects of fimbria lesions on maternal behavior in the rat. Physiology \& Behavior, 21, 89-97.

VOM SAAL, F. S. (1983). Variation in infanticide and parental behavior in male mice due to prior intrauterine proximity to female fetuses: Elimination by prenatal stress. Physiology \& Behavior, 30, 675-681.

WARD, I. L. (1972). Prenatal stress feminizes and demasculinizes the behavior of males. Science, 175, 82-84.

WARD, I. L. (1984). The prenatal stress syndrome: Current status. Psychoneuroendocrinology, 9, 3-11.

WARD, I. L., \& REED, J. (1985). Prenatal stress and prepuberal social rearing conditions interact to determine sexual behavior in male rats. Behavioral Neuroscience, 99, 301-309. 
WARD, I. L., \& WARD, O. B. (1985). Sexual behavior differentiation: Effects of prenatal manipulation in rats. In N. Adler, D. Pfaff, \& R. W. Goy (Eds.), Handbook of behavioral neurobiology (Vol. 7, pp. 77-98). New York: Plenum.

WARD, I. L., \& WEISZ, J. (1980). Maternal stress alters plasma testosterone in fetal males. Science, 207, 328-329.

WARD, I. L., \& WEISZ, J. (1984). Differential effects of maternal stress on circulating levels of corticosterone, progesterone, and testosterone in male and female rat fetuses and their mothers. Endocrinology, 114, 1635-1644.
Ward, O. B., Monaghan, E. P., \& WARD, I. L. (1986). Naltrexone blocks the effects of prenatal stress on sexual behavior differentiation in male rats. Pharmacology, Biochemistry \& Behavior, 25, 573-576.

WeIsz, J., Brown, B. L., \& WARD, I. L. (1982). Maternal stress decreases steroid aromatase activity in brains of male and female rat fetuses. Neuroendocrinology, 35, 374-379.

(Manuscript received February 12, 1988.) 